\title{
INCREASED TENSILE STRENGTH OF CARBON NANOTUBE YARNS AND SHEETS THROUGH CHEMICAL MODIFICATION AND ELECTRON BEAM IRRADIATION
}

Sandi G. Miller, ${ }^{+*}$ Tiffany S. Williams, ${ }^{+}$James S. Baker, ${ }^{\ddagger}$ Francisco Solá, ${ }^{+}$Marisabel LebronColon, ${ }^{+}$Linda S. McCorkle, ${ }^{\S}$ Nathan G. Wilmoth, JJ James Gaier, ${ }^{+}$Michelle Chen, ${ }^{\S}$ and Michael A. Meador ${ }^{+}$

NASA Glenn Research Center Cleveland, $\mathrm{OH} 44135$ 


\section{Background}

- Individual single wall carbon nanotubes (SWCNTs) have been widely investigated for weight reduction in aerospace structures owing to a theoretical tensile strength of $75-135 \mathrm{GPa}$ for an individual SWCNT, and a measured tensile strength of up to $100 \mathrm{GPa}$.

- Recent focus has moved toward fabrication of CNT sheets and yarns with projected application as a drop-in replacement for carbon fiber in composite structures.

- The inherent limitation of macro-scale CNT material strength resides in weak intra-tube (shell to shell) and inter-tube shear interactions. Therefore, increasing material strength at both of these levels is crucial to development of high strength CNT material forms.

- We have investigated the combined effects of small molecule functionalization together with e-beam generated cross-linking in an attempt to further increase the tensile properties of CNT sheets and yarns. 


\section{CNT Sheet Material}

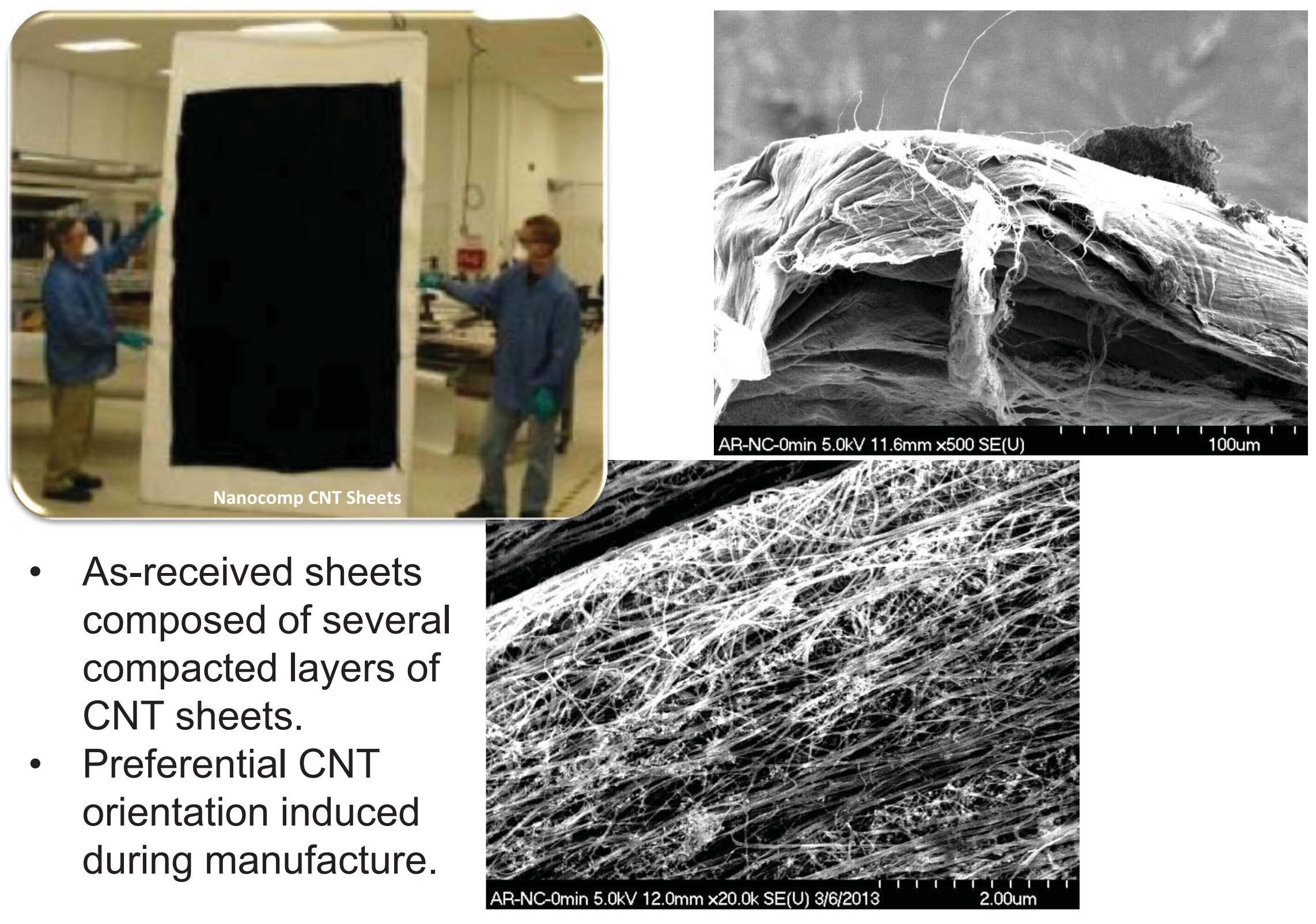




\section{CNT Yarn Material}

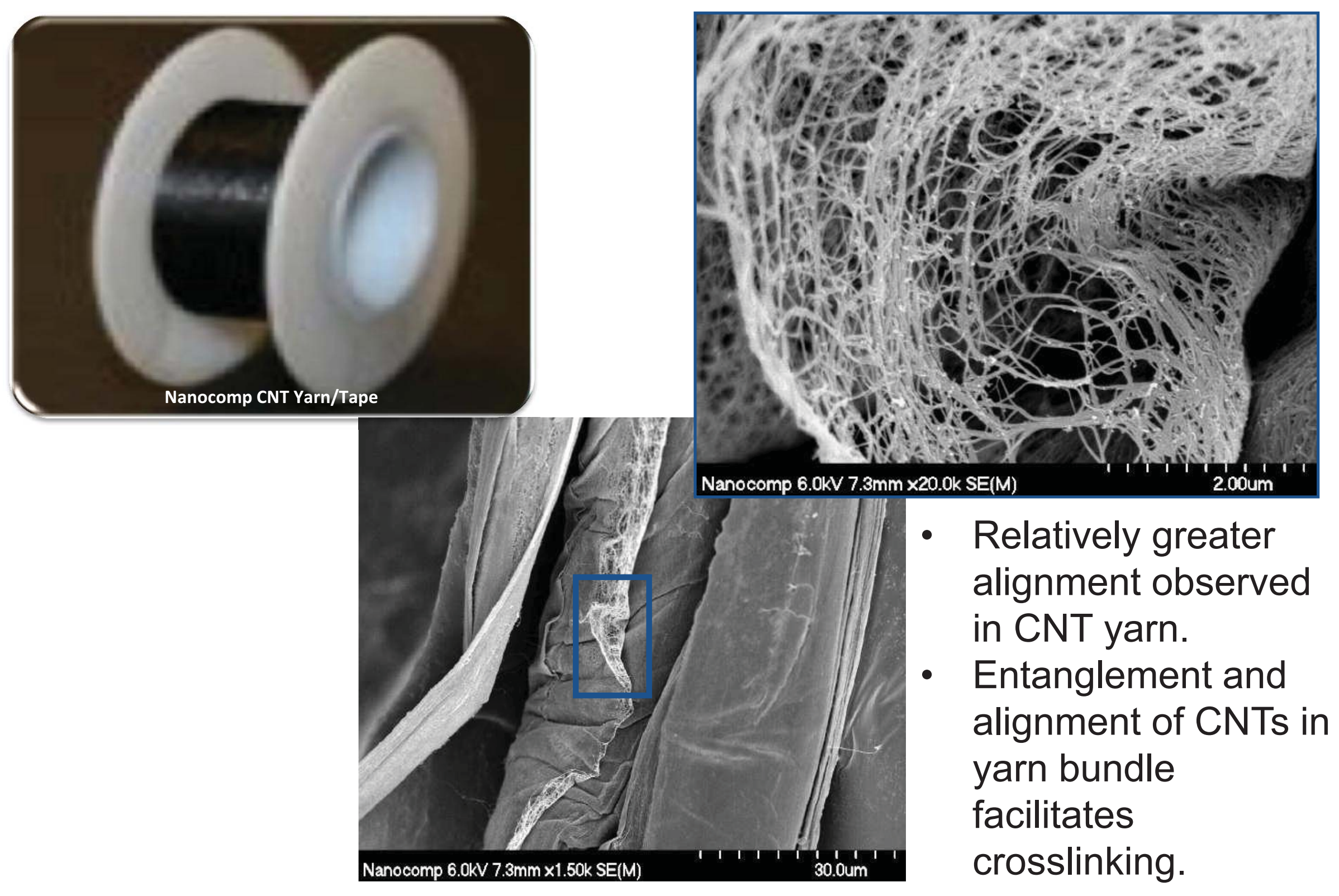




\section{Post-Processing Methodology}

- Pre-strain to increase CNT packing density and alignment.

- Small molecule functionalization

- Electron Beam Crosslinking

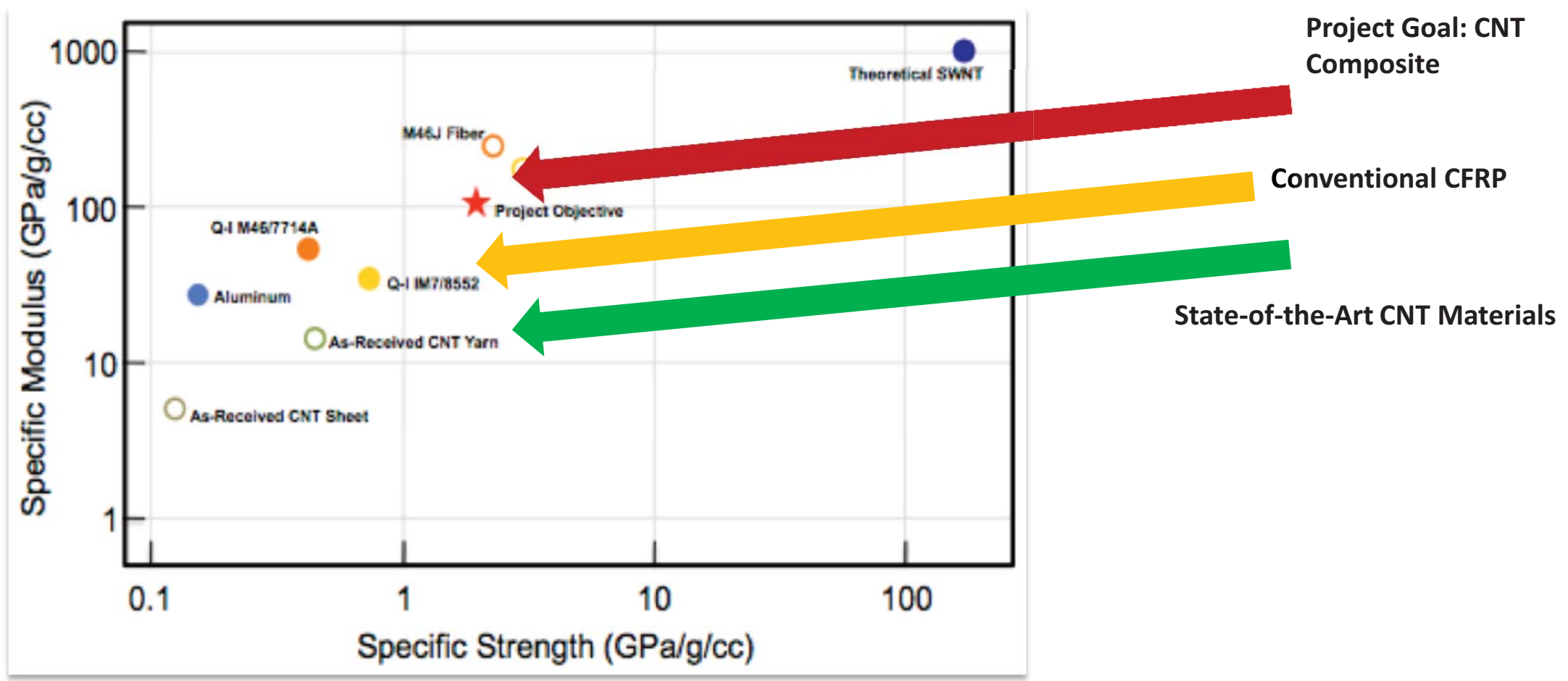




\section{Post Processing- Strain}

DMA Tensile Data Following Stretching/ Densification

Tensile stress of the CNT Sheet after stretched (ca. 12\%) and densification (using acetone) had an increase $>200 \%$.
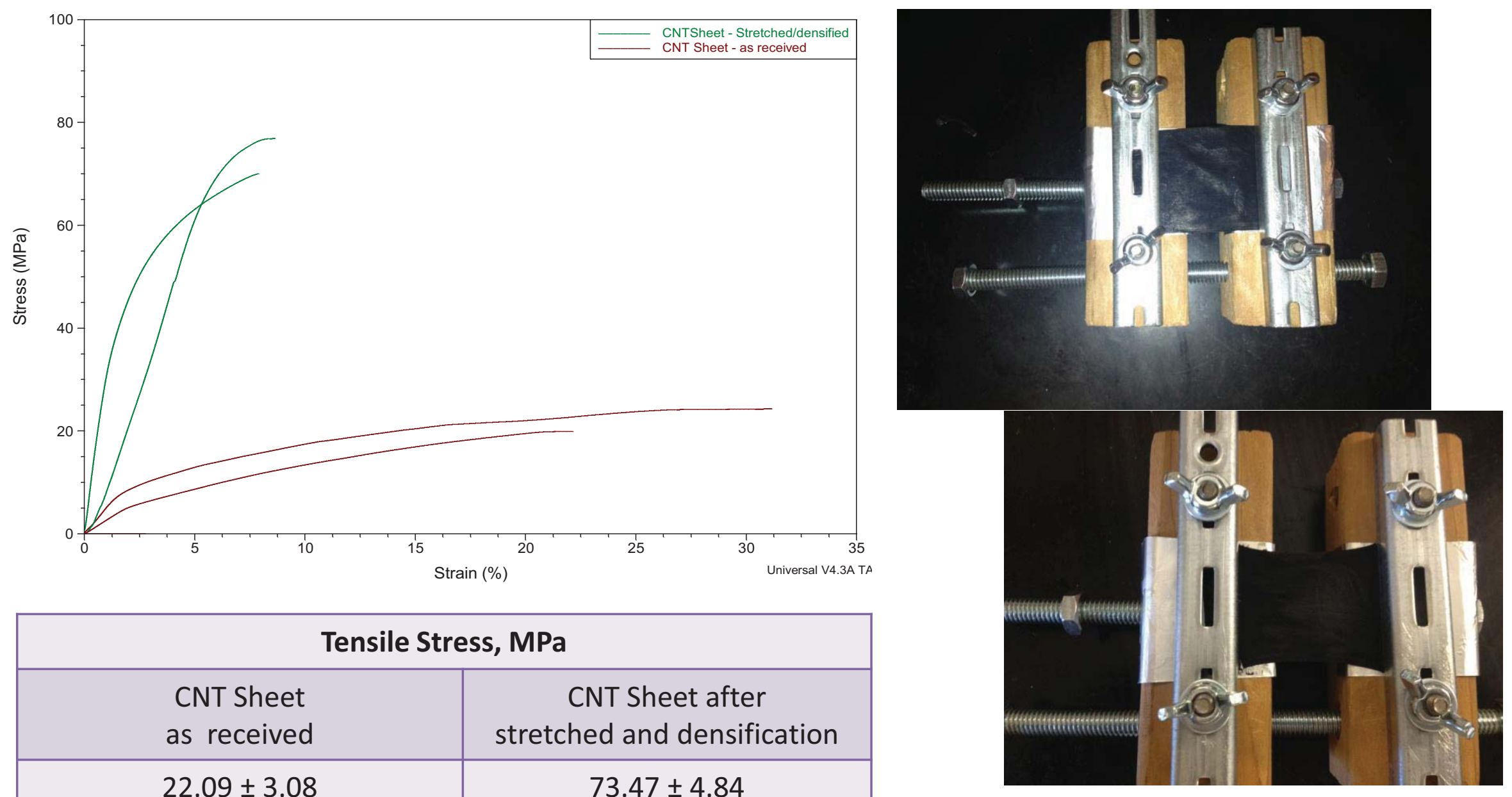

\begin{tabular}{|c|c|}
\hline \multicolumn{2}{|c|}{ Tensile Stress, MPa } \\
\hline $\begin{array}{c}\text { CNT Sheet } \\
\text { as received }\end{array}$ & $\begin{array}{c}\text { CNT Sheet after } \\
\text { stretched and densification }\end{array}$ \\
\hline $22.09 \pm 3.08$ & $73.47 \pm 4.84$ \\
\hline
\end{tabular}




\section{Post Processing- Small Molecule Functionalization}
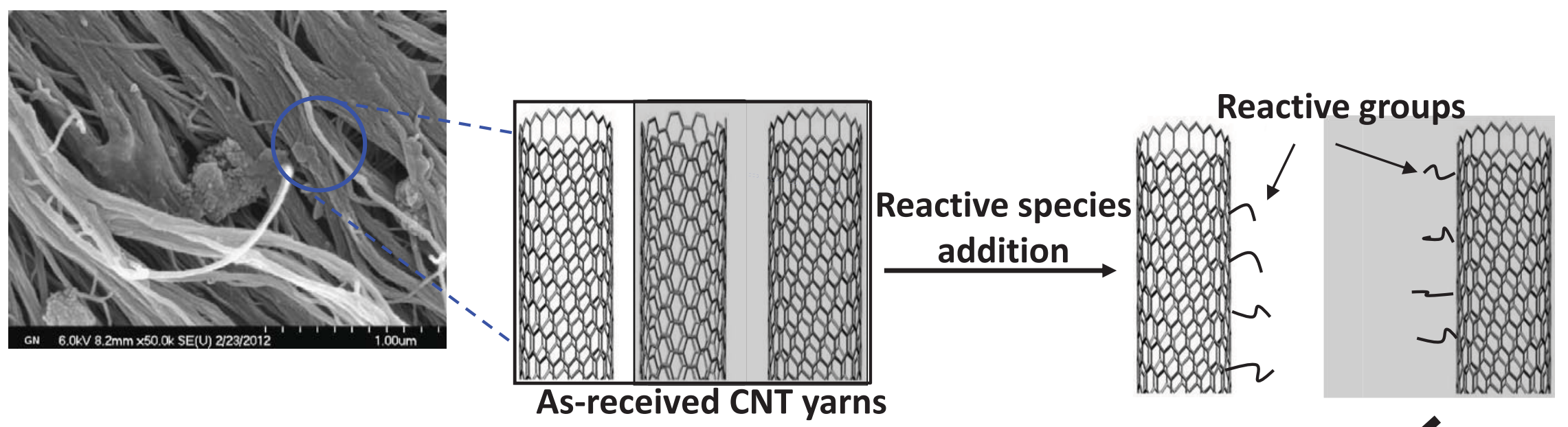

CNT were functionalized with

(1) amine and (2) hydroxyl reactive sites. These were chosen to bond with the epoxy matrix that will be used to make composite materials.

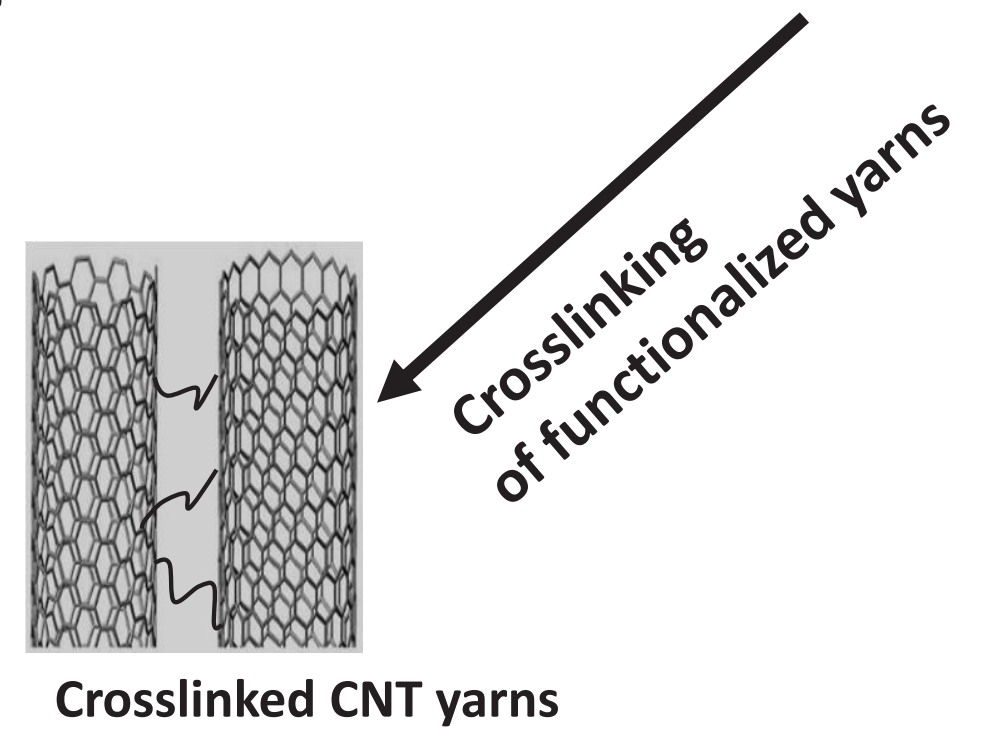




\section{Post Processing- Electron Beam Exposure}

\section{Exposure levels}

- $1 \times 10^{15} \mathrm{e} / \mathrm{cm}^{2}$

$-90 \mathrm{sec}$

- $4.8 \times 10^{16} \mathrm{e} / \mathrm{cm}^{2}$

$-20 \mathrm{~min}$

- $9.6 \times 10^{16} \mathrm{e} / \mathrm{cm}^{2}$

$-40 \mathrm{~min}$

- $2.2 \times 10^{17} \mathrm{e} / \mathrm{cm}^{2}$

$-90 \mathrm{~min}$

Intermediate exposure levels also investigated.

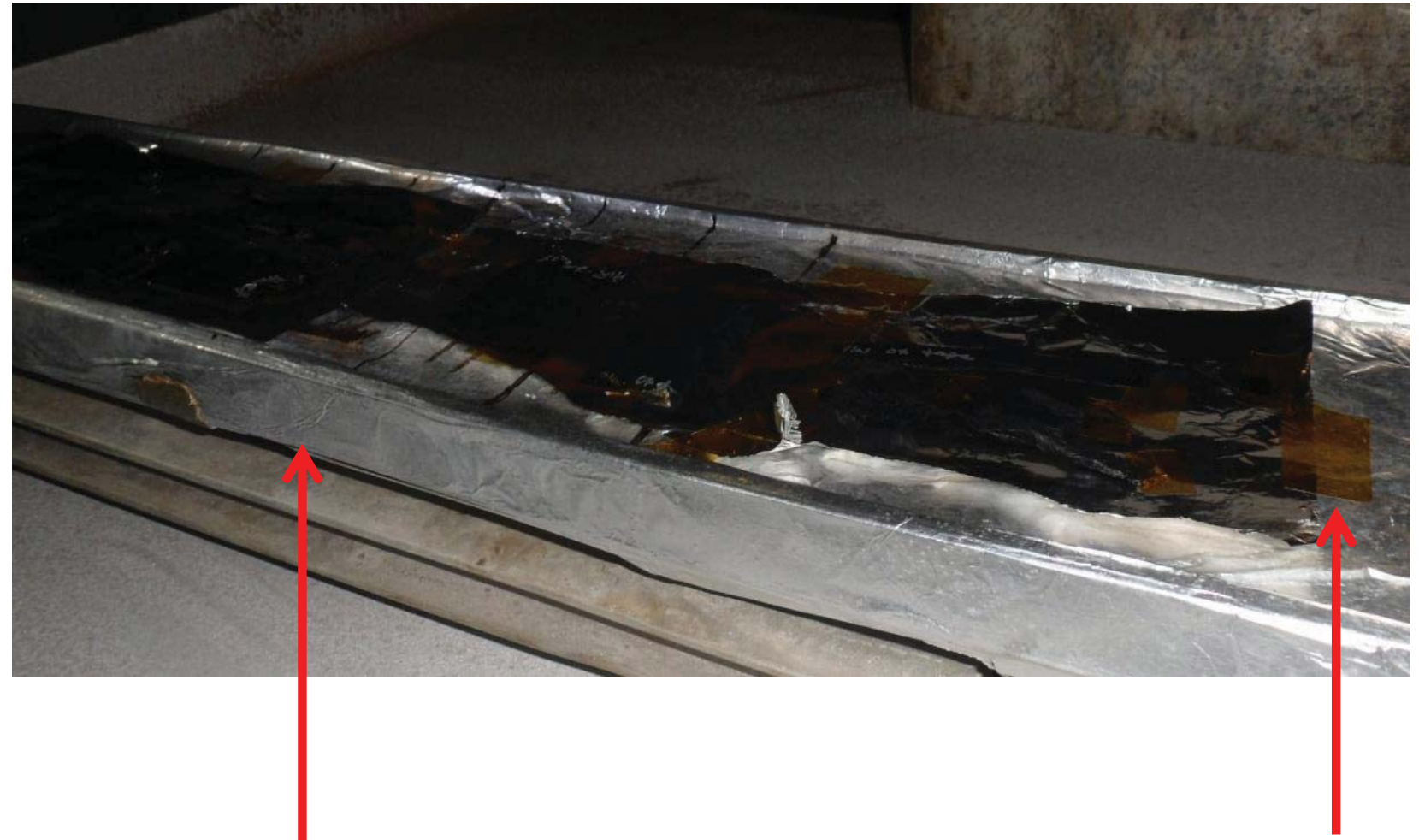

Water cooled Aluminum Plate
CNT material held in place with Kapton tape 


\section{Post Modification Characterization Thickness/Diameter Measurement}

\begin{tabular}{|c|c|c|c|}
$\begin{array}{c}\text { Sheet Thickness/ } \\
\text { E-beam exposure } \\
\text { time }\end{array}$ & $\begin{array}{c}\text { As Received } \\
(\mathbf{m m})\end{array}$ & $\begin{array}{c}\text { Amine } \\
\text { Functionalized } \\
(\mathbf{m m})\end{array}$ & $\begin{array}{c}\text { Hydroxyl } \\
\text { Functionalized } \\
(\mathbf{m m})\end{array}$ \\
\hline $\mathbf{0} \mathrm{min}$ & $16.8 \pm 3.1$ & $18.0 \pm 2.1$ & $15.8 \pm 2.9$ \\
\hline $20 \mathrm{~min}$ & $20.0 \pm 2.2$ & $18.3 \pm 2.1$ & $18.7 \pm 1.3$ \\
\hline $40 \mathrm{~min}$ & $20.3 \pm 2.6$ & $15.4 \pm 3.0$ & $16.1 \pm 1.9$ \\
\hline $90 \mathrm{~min}$ & $20.5 \pm 3.4$ & $18.0 \pm 1.8$ & $17.0 \pm 1.7$ \\
\hline $\begin{array}{c}\text { Yarn Diameter/ } \\
\text { E-beam exposure }\end{array}$ & $\begin{array}{c}\text { As Received } \\
(\mathrm{mm})\end{array}$ & $\begin{array}{c}\text { Amine } \\
\text { Functionalized } \\
\text { time }\end{array}$ & $\begin{array}{c}\text { Hydroxyl } \\
\text { Functionalized } \\
(\mathrm{mm})\end{array}$ \\
\hline 0 min & $67.0 \pm 5.0$ & $63.0 \pm 5.4$ & $66.7 \pm 10.7$ \\
\hline $20 \mathrm{~min}$ & $63.2 \pm 8.3$ & $66.3 \pm 8.3$ & $64.7 \pm 6.7$ \\
\hline $40 \mathrm{~min}$ & $62.2 \pm 3.4$ & $64.5 \pm 3.7$ & $73.6 \pm 6.3$ \\
\hline $90 \mathrm{~min}$ & $60.0 \pm 4.8$ & $65.8 \pm 4.1$ & $63.4 \pm 5.0$ \\
\hline
\end{tabular}




\section{Post Modification Characterization- RAMAN and XPS}

\begin{tabular}{|c|c|c|c|c|c|c|}
\hline \multirow[t]{2}{*}{ SHEET } & \multicolumn{2}{|c|}{ Un-functionalized } & \multicolumn{2}{|c|}{$\begin{array}{c}\text { Amine } \\
\text { Functionalized }\end{array}$} & \multicolumn{2}{|c|}{$\begin{array}{c}\text { Hydroxyl } \\
\text { Functionalized }\end{array}$} \\
\hline & $\mathrm{I}_{\mathrm{G} / \mathrm{D}}$ & $\mathrm{C} / \mathrm{O}$ & $I_{G / D}$ & $\mathrm{C} / \mathrm{O}$ & $I_{G / D}$ & $\mathrm{C} / \mathrm{O}$ \\
\hline $0 \mathrm{~min}$ & $3.0 \pm 0.2$ & 44.0 & $2.3 \pm 0.2$ & 23.4 & $3.3 \pm 0.5$ & 17.0 \\
\hline $20 \mathrm{~min}$ & $1.5 \pm 0.5$ & 37.2 & $1.7 \pm 0.1$ & 10.4 & $1.5 \pm 0.1$ & 10.5 \\
\hline $40 \mathrm{~min}$ & $1.7 \pm 0.7$ & 6.5 & $0.7 \pm 0.1$ & 6.5 & $1.3 \pm 0.5$ & 5.4 \\
\hline $90 \mathrm{~min}$ & $0.9 \pm 0.2$ & 9.6 & $1.4 \pm 0.1$ & 5.2 & $0.8 \pm 0.1$ & 4.8 \\
\hline YARN & \multicolumn{2}{|c|}{$0 \mathrm{~min}$} & $20 \mathrm{~min}$ & \multicolumn{2}{|c|}{$40 \mathrm{~min}$} & $90 \mathrm{~min}$ \\
\hline As- Received & \multicolumn{2}{|c|}{$4.8 \pm 1.7$} & $1.7 \pm 0.2$ & \multicolumn{2}{|c|}{$1.5 \pm 0.1$} & $1.0 \pm 0.1$ \\
\hline $\begin{array}{c}\text { Hydroxyl } \\
\text { Functionalized }\end{array}$ & \multicolumn{2}{|c|}{$5.2 \pm 1.6$} & $1.6 \pm 0.7$ & \multicolumn{2}{|c|}{$2.1 \pm 0.2$} & $1.4 \pm 0.1$ \\
\hline $\begin{array}{c}\text { Amine } \\
\text { Functionalized }\end{array}$ & \multicolumn{2}{|c|}{$2.2 \pm 0.8$} & $2.4 \pm 0.3$ & \multicolumn{2}{|c|}{$1.3 \pm 0.1$} & $1.1 \pm 0.1$ \\
\hline
\end{tabular}




\section{Post Modification Characterization RAMAN}

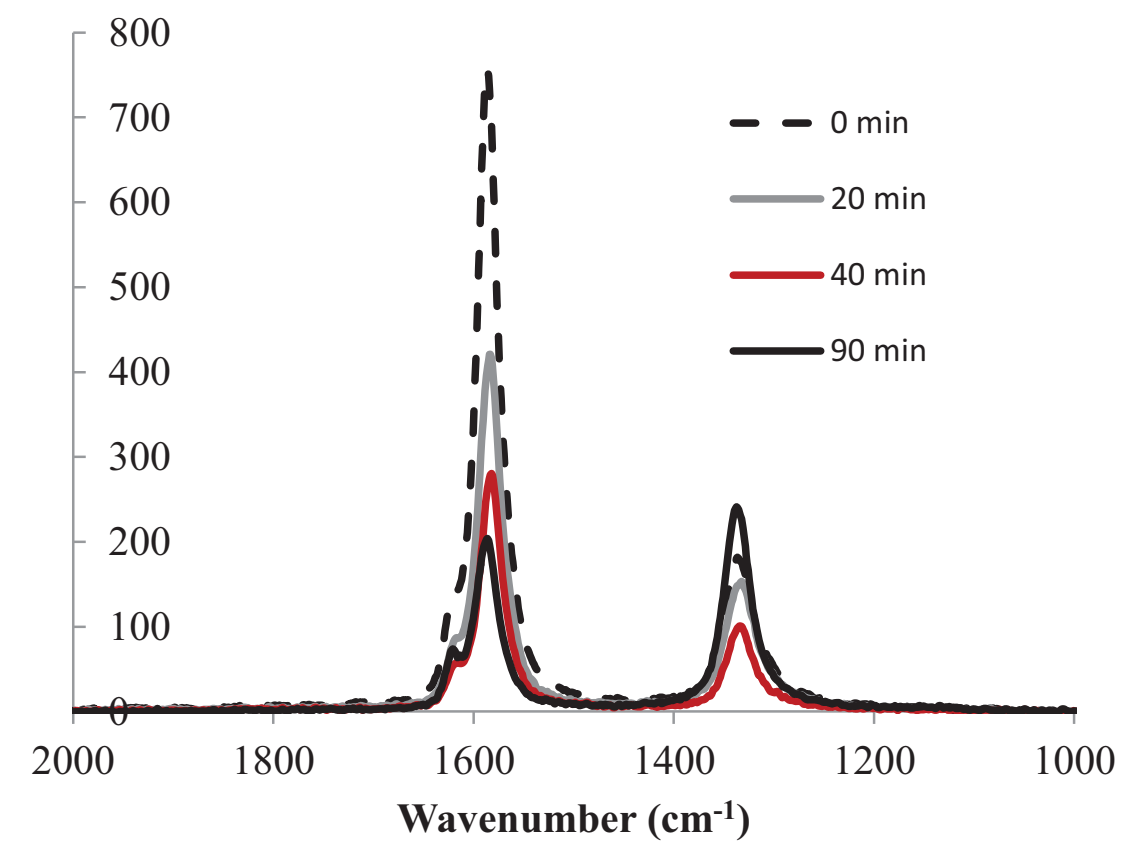

Effect of e-beam irradiation on the G/D ratio of as-received CNT sheet.

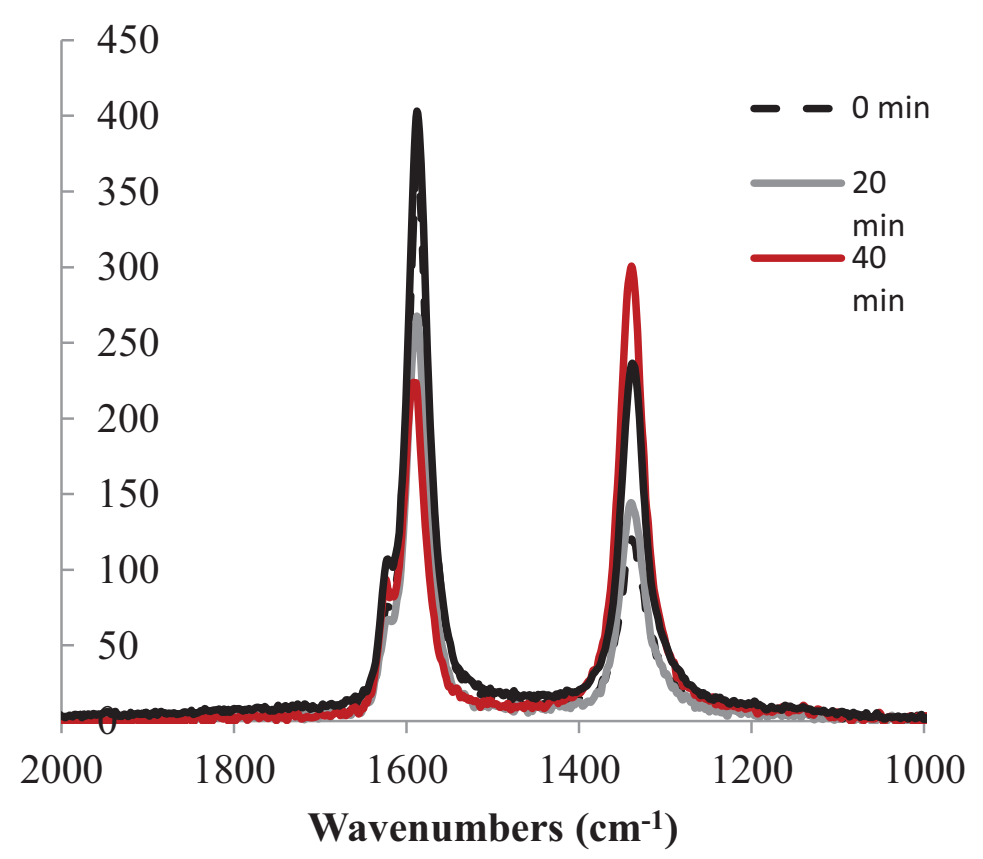

Effect of e-beam irradiation on the G/D ratio of 3-aminopropyl functionalized CNT sheet. 


\section{Tensile Test Showed Trend of Increasing Strength with Irradiation and Functionalization}
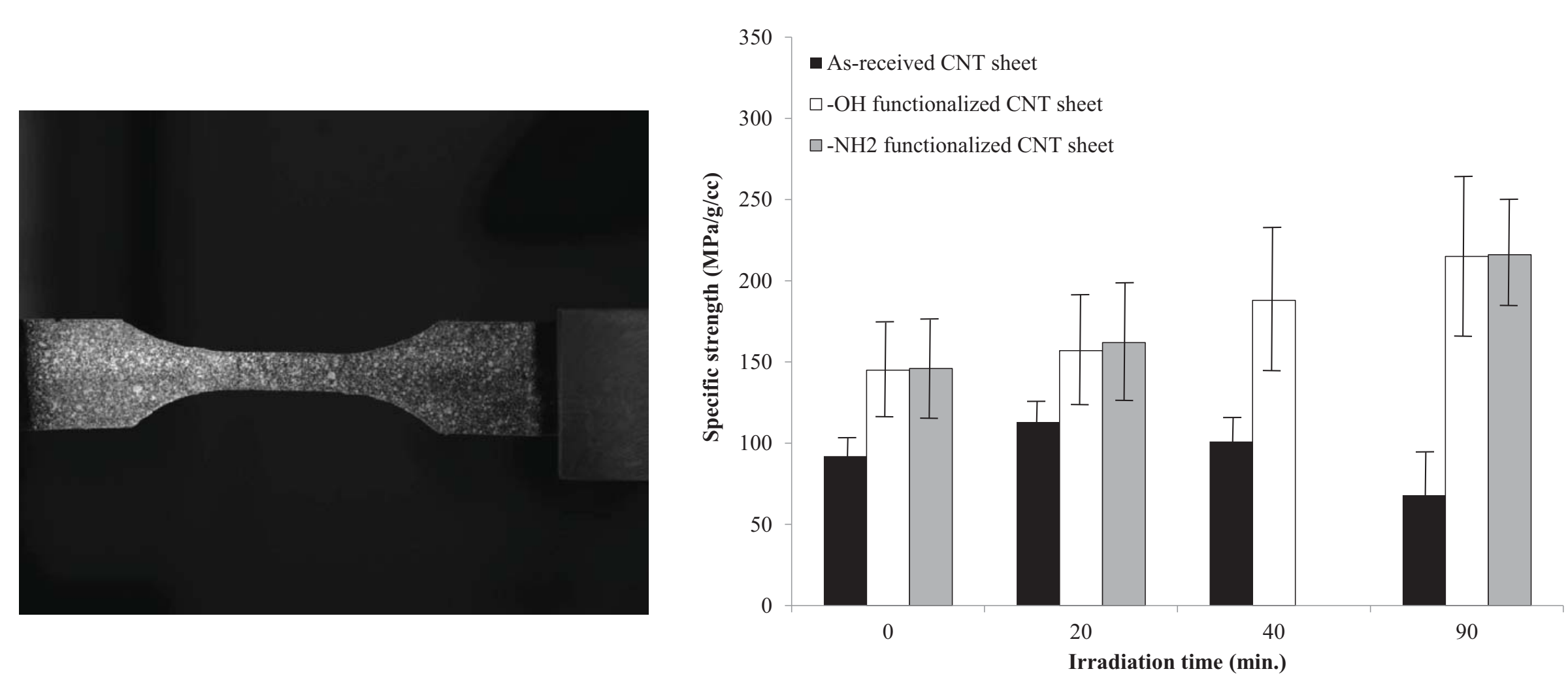

Functionalized sheet material strength was increased with all irradiation doses. The unfunctionalized material demonstrated a limit below 90 min of exposure. Sheets were prestrained. 


\section{Tensile Tests of Yarn Material}
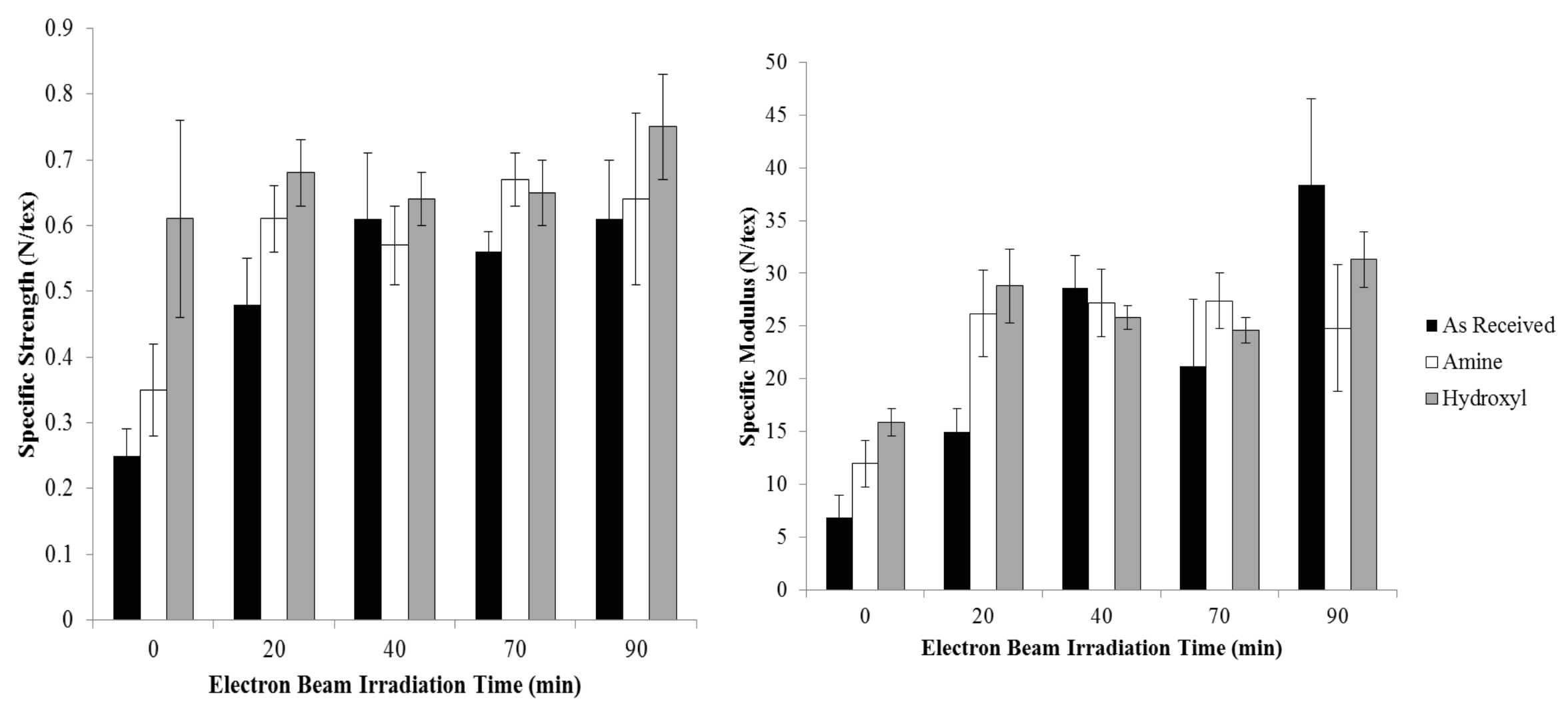

Both strength and modulus increased with functionalization and irradiation time. This was attributed to greater CNT alignment and entanglement within the yarn material relative to the sheet form. 


\section{SEM Characterization of Yarn Fracture Surface}
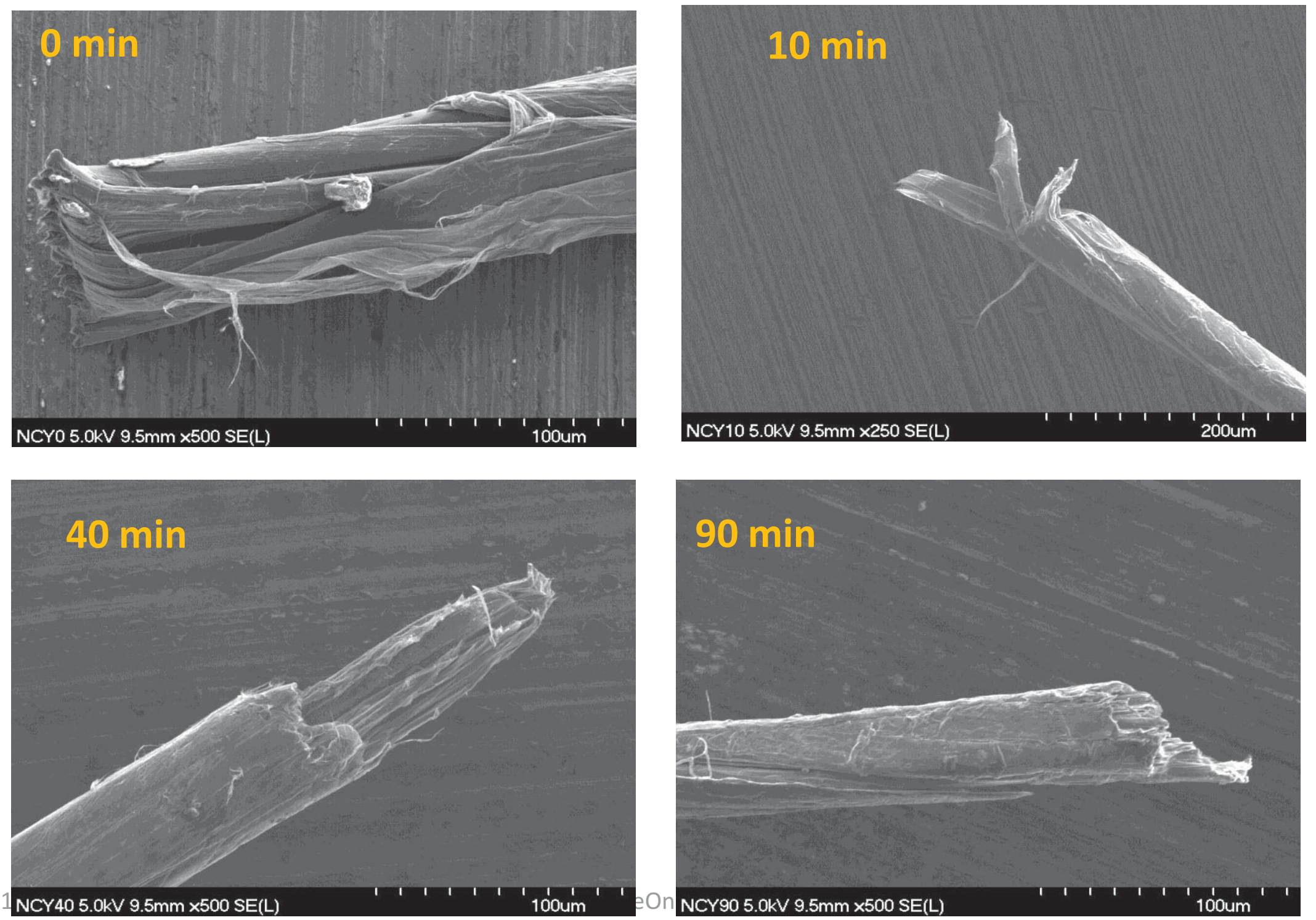


\section{Focused Ion Beam Images Show CNT Yarn Morphology}

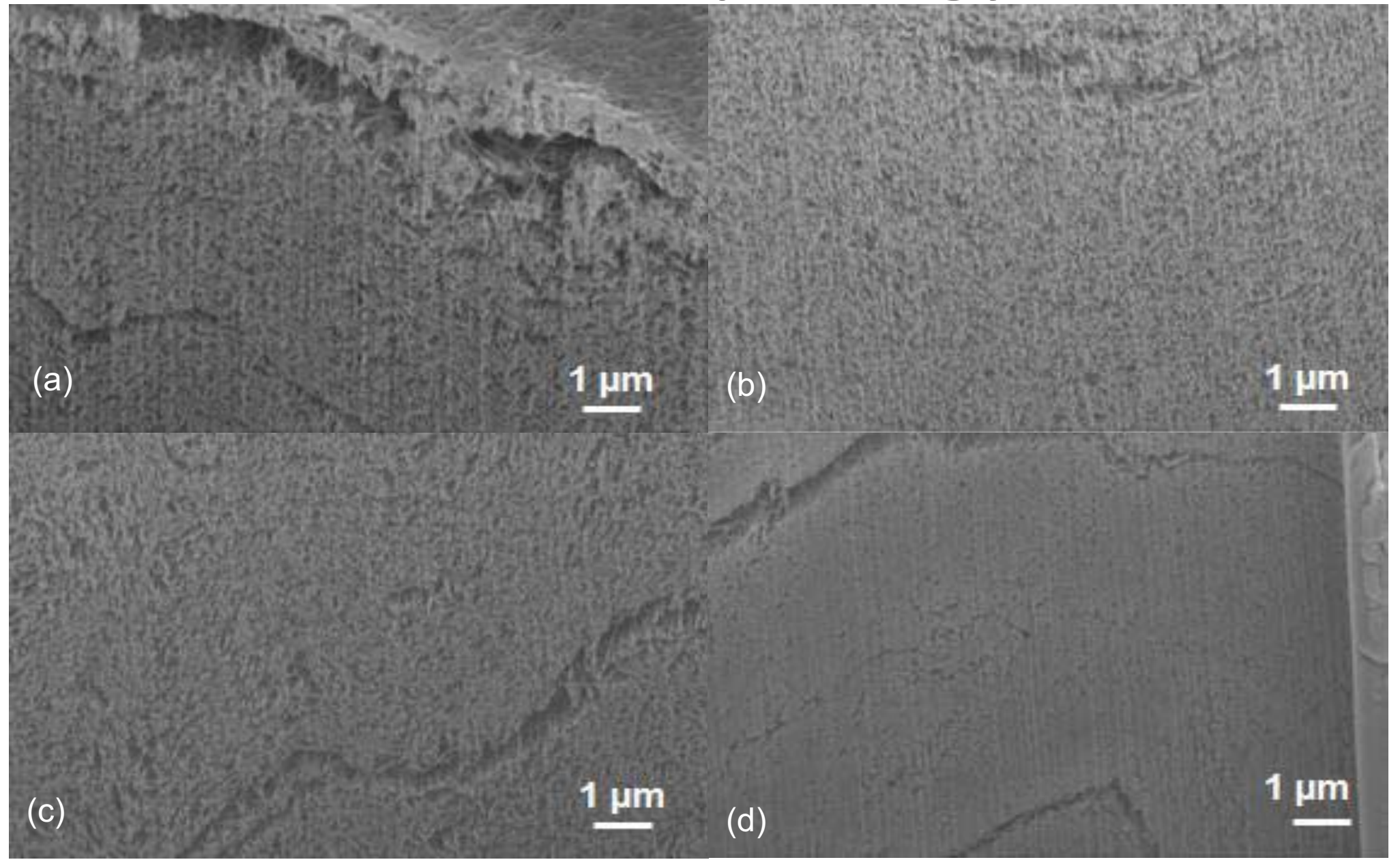

FIB microscopy images of CNT yarn interior morphology following irradiation at (a) 0 min. (b) 20 min., (c) 40 min., and (d) 90 min. 


\section{Influence of Resin Infiltration and Tensile Testing}

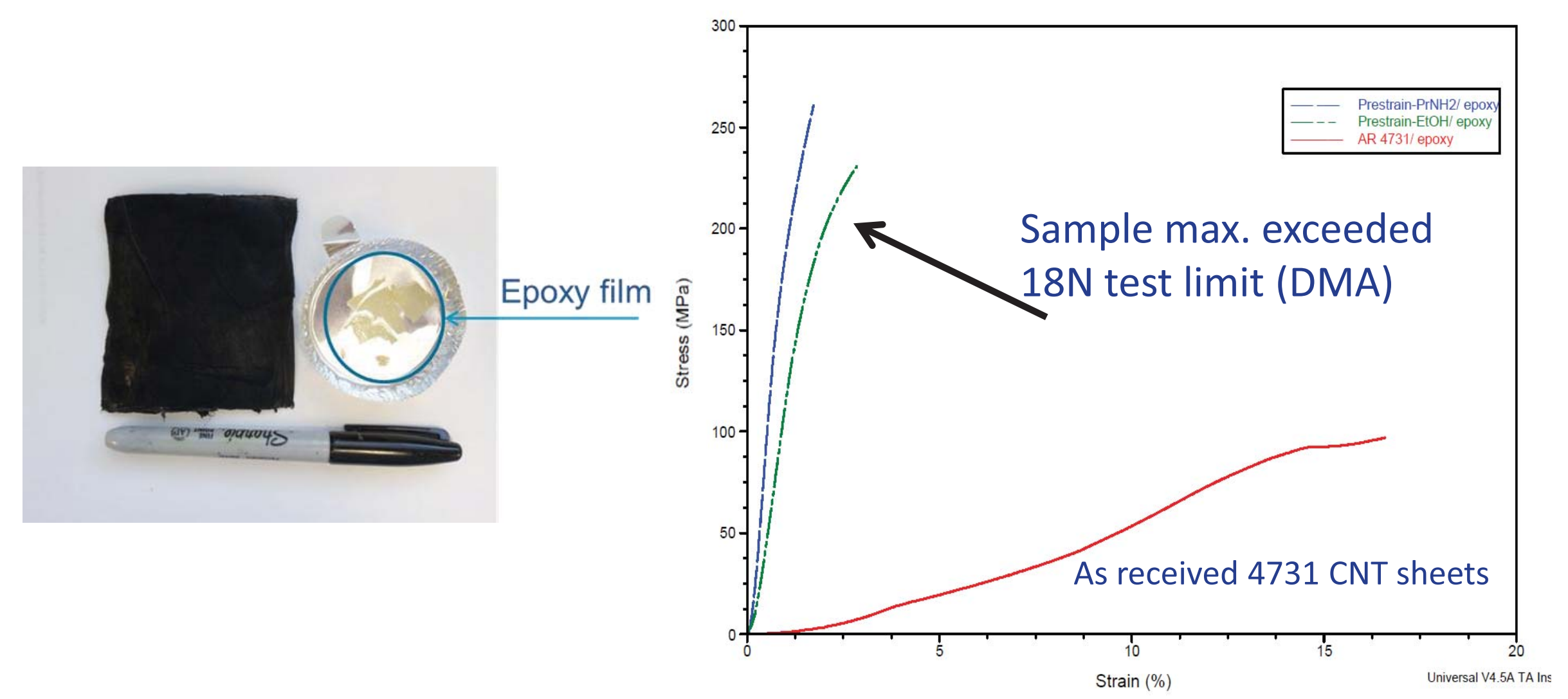

Solvent casting of epoxy into single ply CNT sheets: Dichloromethane was used as the solvent for the resin film casting. The polymer solution was dispensed over the CNT sheet, and a metal block was placed over the CNT sheet during curing. (This sheet was not pre-strained prior to testing) 


\section{Single Ply Composite Tensile Tests}
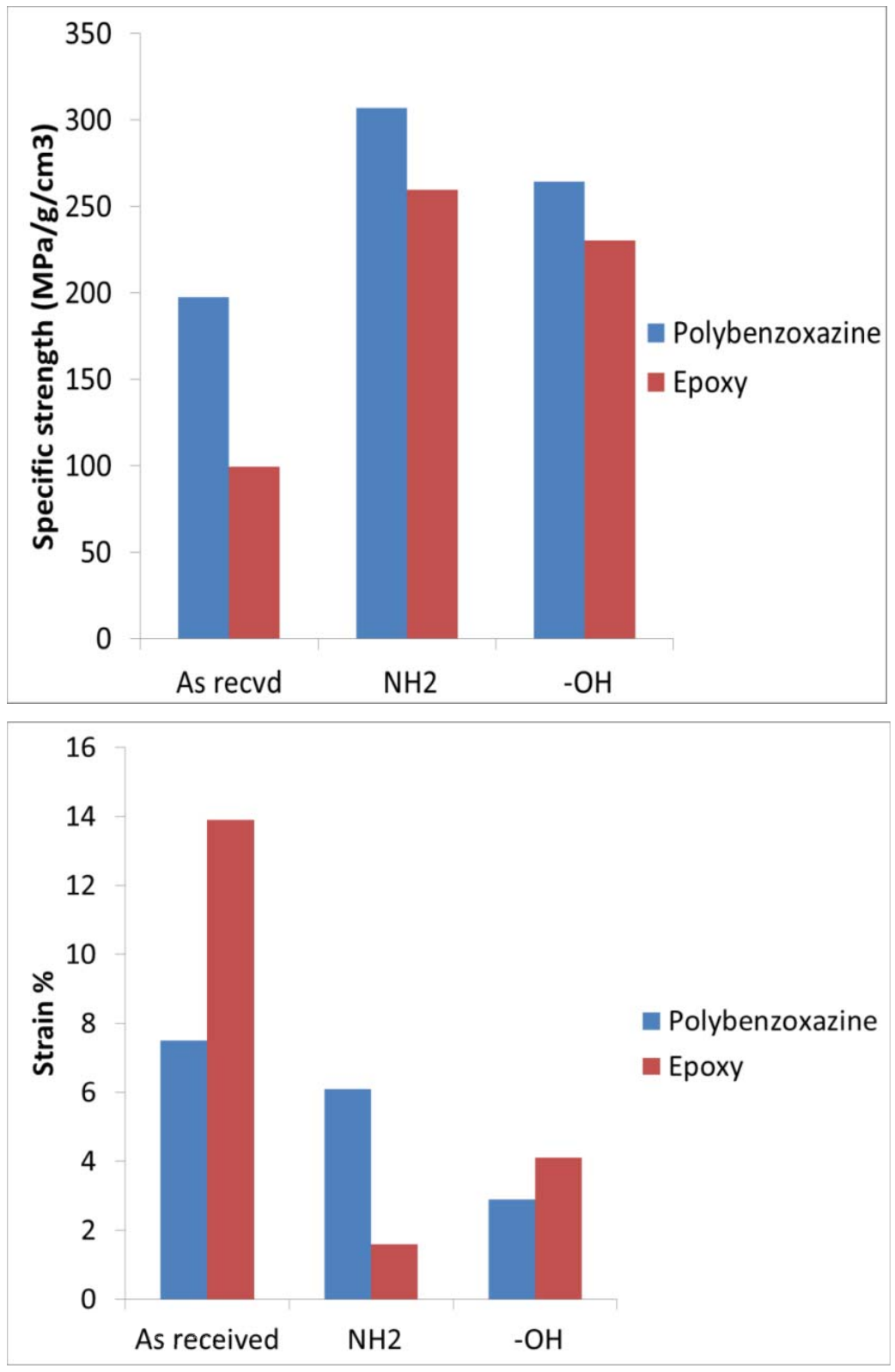

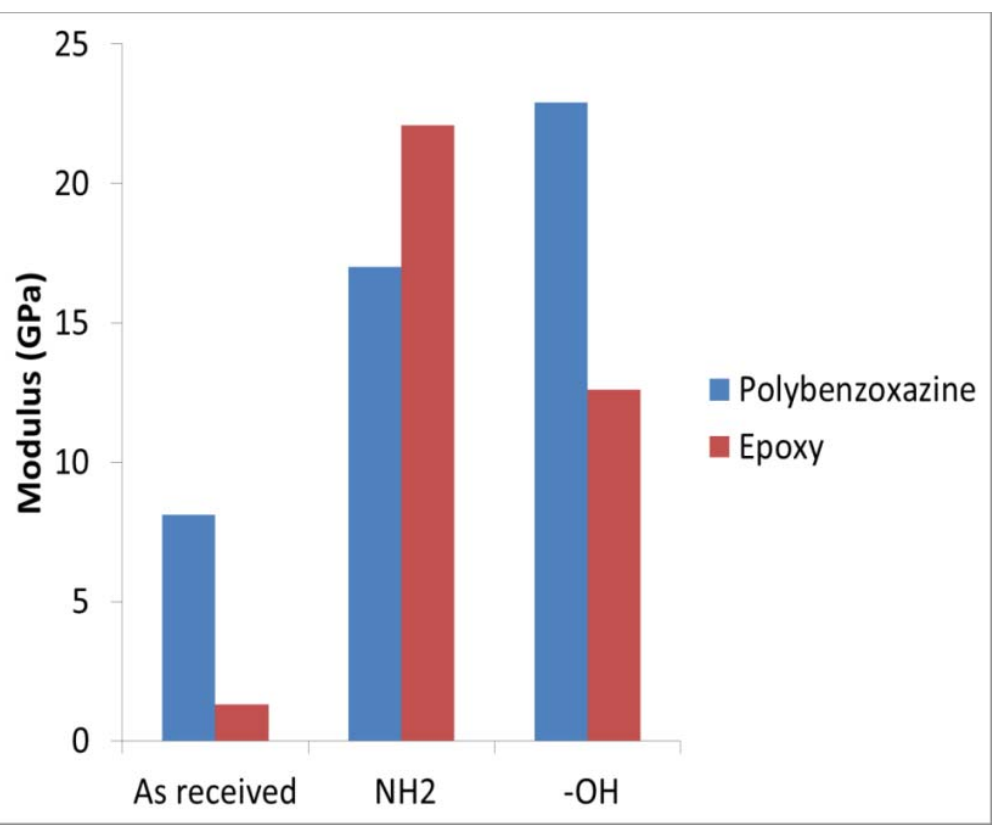

The specific strength of polybenzoxazine- as received CNT sheet composites was $98 \%$ higher than that of epoxy- as received CNT sheet

Functionalization of CNT sheets resulted in at least a $130 \%$ improvement in specific tensile strength compared to samples that were not functionalized

Functionalization of CNT sheets resulted in a significant increase in the modulus of polybenzoxazine and epoxy resin infused nanocomposites 


\section{Characterization of CNT Sheet Consolidation Following Resin Infusion}

Two stretched CNT sheets were infiltrated with a polybenzoxazine resin and stacked to prepare a 2-ply laminate. Resin content was $\sim 45 \%$. The cross-section was examined by optical microscopy to detect consolidation issues such as voids in the inter-ply region. The panel appeared well consolidated and additional panels will be fabricated with functionalized sheets.

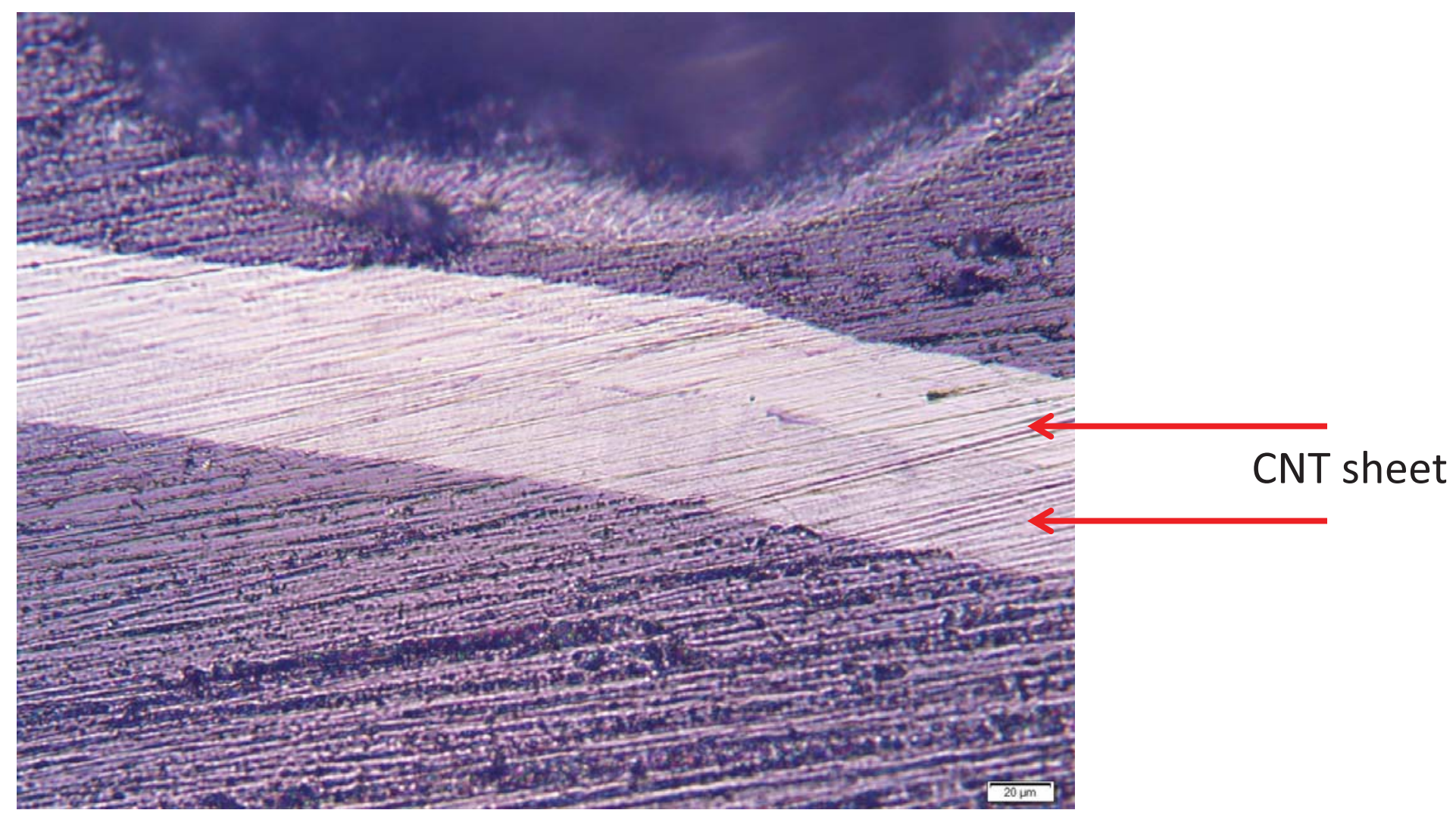




\section{Summary}

- The influence of small molecule modification and e-beam irradiation on CNT sheet and yarn material was evaluated.

- Both processes tended to reduce the $\mathrm{I}_{\mathrm{G} / \mathrm{D}}$ ratio due to disruption of the $s p^{2}$ hybridization of the pristine CNT material.

- E-beam irradiation of an as-received, bulk CNT sheet material negatively impacted the material tensile strength when exposed to an e-beam flux of $2.2 \mathrm{x}$ $10^{17} \mathrm{e} / \mathrm{cm}^{2}(90 \mathrm{~min})$. However the same exposure increased the specific strength of the functionalized materials by nearly $60 \%$.

- Irradiation of as-received yarn, led to an increase in tensile strength, through tube alignment and entanglement.

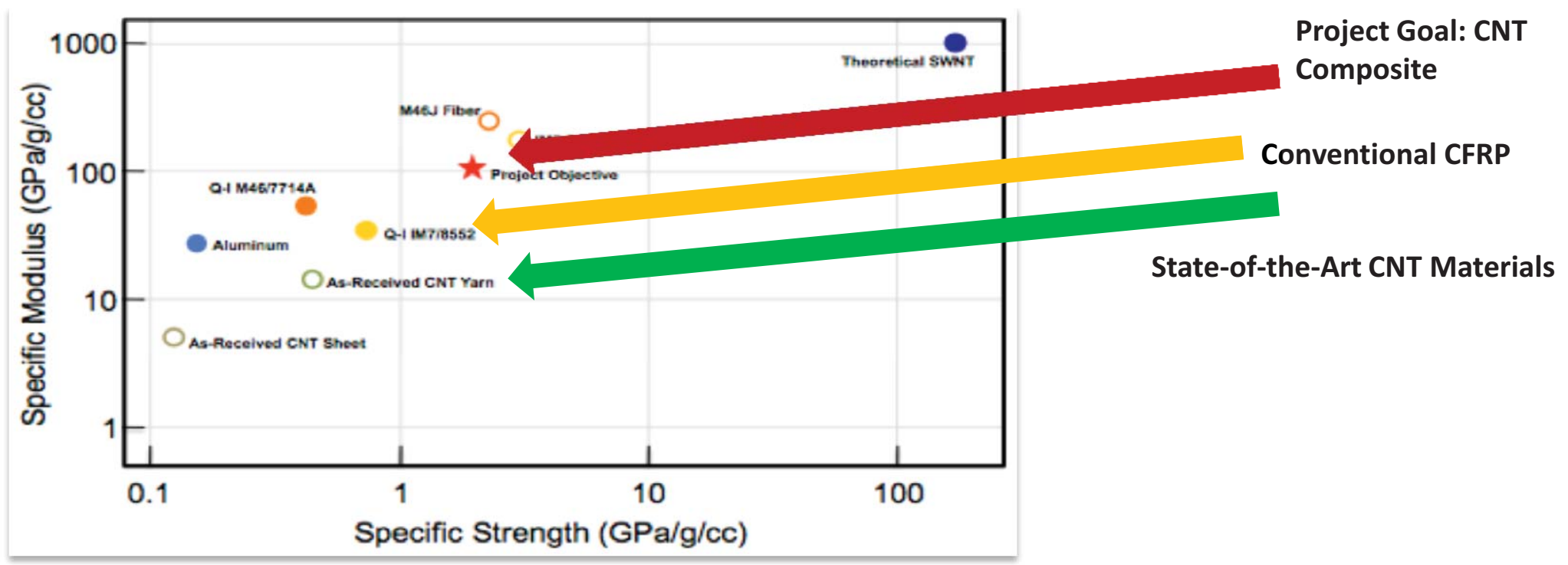




\section{Acknowledgements}

Game Changing Development Program/ Nanotechnology Project 